\title{
Expression and clinical significance of PD-1 in hepatocellular carcinoma tissues detected by a novel mouse anti-human PD-1 monoclonal antibody
}

\author{
ZIWEI LI $^{1 *}$, BIN LI $^{1 *}$, DAN PENG $^{1}$, HAIYAN XING ${ }^{1}$, GUANYING WANG $^{1}$, \\ PAN LI ${ }^{1}$, JIMING WANG ${ }^{2}$, GEORGE YE $^{3}$ and JIANHONG CHEN ${ }^{1}$
}

\author{
${ }^{1}$ Department of Pharmacy, Daping Hospital and Research Institute of Surgery, Third Military Medical University, \\ Chongqing 400042, P.R. China; ${ }^{2}$ Cancer and Inflammation Program, Center for Cancer Research, \\ National Cancer Institute, Frederick, MD 21702, USA; ${ }^{3}$ Yes Biotech Laboratories Ltd., \\ Mississauga, ON L5S 1V6, Canada
}

Received October 23, 2017; Accepted March 26, 2018

DOI: 10.3892/ijo.2018.4358

\begin{abstract}
Hepatocellular carcinoma (HCC) is one of the most common malignancies and causes of death worldwide. Research investigating novel therapeutic strategies for the treatment of $\mathrm{HCC}$ is urgently required. Monoclonal antibodies (mAbs) that target the programmed cell death-1 (PD-1/PDCD1)/ programmed death-ligand 1 (PD-L1) immune checkpoint have demonstrated substantial clinical benefit for a variety of solid tumors; however, these mAbs have not been well studied in HCC. In the present study, Sp2/0-Ag14 myeloma cells and spleen cells derived from $\mathrm{BALB} / \mathrm{c}$ mice immunized with the recombinant human PD-1/PDCD1 protein were fused for the production of novel antibodies. The 9E11 mAb, which exhibited the highest specificity for PD-1 in HCC tissues in western blot and immunohistochemical staining analyses, was used to investigate the clinical significance of PD-1 expression in HCC tissues from 77 cases, which were collected and examined histologically. Overexpression of PD-1 was identified in peritumoral tissues, primarily in the liver portal region. Importantly, by analyzing the clinical data from $77 \mathrm{HCC}$ patients, the expression of PD-1 was observed to be significantly correlated with larger tumor size $(>5 \mathrm{~cm})$ and poorly differentiated tumors. In addition, PD-1 expression was moderately correlated with venous thrombosis, but not correlated with patient sex or age, liver cirrhosis, hepatitis B, tumor, node and metastasis (TNM) stage or tumor location. The results of the present study suggest
\end{abstract}

Correspondence to: Dr Jianhong Chen, Department of Pharmacy, Daping Hospital and Research Institute of Surgery, Third Military Medical University, 10 Changjiangzhilu, Chongqing 400042, P.R. China

E-mail: chenjhlab@163.com

*Contributed equally

Key words: programmed cell death-1, monoclonal antibody, immunosuppression, hepatocellular carcinoma that high-level PD-1 expression may be an important factor associated with the immune checkpoint pathway in HCC. The results suggest that PD-1 serves an important role in tumor immune evasion and may be a valuable immunodiagnostic marker. In addition, PD-1 may serve as a therapeutic target for patients presenting with poorly differentiated HCC, thus indicating the potential application of a PD-1 inhibitor for the treatment of HCC patients.

\section{Introduction}

Programmed cell death-1 (PD-1/PDCD1), also known as CD279, is a 288-amino acid cell surface protein that belongs to the immunoglobulin superfamily. PD-1 is expressed by immune cells, including T cells, B cells and macrophages (1). High-level expression of the PD-1 ligand (CD274 or B7-H1) in tumor cells has been found to be associated with increased tumor aggressiveness and poor prognosis $(2,3)$. When PD-1 binds its ligand, immune cell activation and effector function are attenuated $(4,5)$. The PD-1/programmed death-ligand 1 (PD-L1) pathway is associated with cancer immune-evasion, autoimmunity, and Listeria monocytogenes infection (6). Previous studies have implicated PD-L1 interactions in immune-attenuation at peripheral sites outside lymphatic organs $(7,8)$. As antibodies are natural antagonists, inhibition of the PD-1/PD-L1 signaling pathway with antibodies may improve host tumor clearance and restore the immune function of lymphocytes. This presents a novel direction for antitumor immunotherapy.

A number of monoclonal antibodies (mAbs) targeting the PD-1/PD-L1 checkpoint are undergoing clinical trials, and have thus far exhibited encouraging therapeutic effects $(6,8,9)$. However, the low response rate in a small number of cancer patients limits their utilization (10-13). In addition, adverse events have frequently been observed during antibody treatment, such as antibody-dependent cellmediated cytotoxicity (14-16), which reduces the effectiveness of the therapy and restricts clinical application. Therefore, it is important to develop mAbs with reduced toxicity for the 
immunotherapeutic treatment of patients with cancer, and to determine how to maximize their efficacy.

PD-1/PD-L1-targeting therapy has been used in recent years for the treatment of a variety of solid tumors, including nonsmall cell lung cancer $(17,18)$, malignant melanoma $(19,20)$, urothelial carcinoma $(21,22)$, triple-negative breast cancer (23), lymphoma (24) and head and neck cancer (25). However, the application of PD-1/PD-L1 checkpoint inhibitors in hepatocellular carcinoma (HCC) is not well reported. In addition, studies have demonstrated that abnormal PD-L1 expression in tumor tissues is significantly associated with the degree of tumor malignancy, poor prognosis and low survival rates (26-30). However, the clinical significance of PD-1 expression in HCC tissues is not well understood, and it remains to be determined whether PD-1 may be used as a biomarker for the immunotherapeutic treatment of HCC. Therefore, in the present study, a novel PD-1 mAb (9E11) with the most sensitive experimental effects in immunohistochemistry (IHC) was selected as the primary antibody to detect the expression of PD-1 in HCC tissues by IHC. In addition, the correlation between PD-1 expression in HCC tissues and the clinicopathological features of patients was assessed, in order to explore the potency of an anti-PD-1 monoclonal antibody as an immunotherapeutic agent for the treatment of HCC. These results may facilitate the application of anti-PD-1 monoclonal antibody in the immunotherapeutic treatment of patients with HCC.

\section{Materials and methods}

Clinical specimens. HCC tissue specimens from 77 cases (64 males and 13 females), collected between January and December 2014 from the Pathology Department of the Daping Hospital Third Military Medical University (Chongqing, China), were fixed in formalin and embedded in paraffin. All patients included in the analysis were diagnosed with HCC following surgery and had received no adjuvant radiotherapy, chemotherapy, biological therapy or other treatments. HCC was staged according to the Union for International Cancer Control/American Joint Committee On Cancer 2010 tumor, node and metastasis (TNM) staging criteria. This project was conducted in accordance with the Declaration of Helsinki and was approved by the Ethics Committee of Daping Hospital and Research Institute of Surgery, Third Military Medical University. Written informed consent was obtained from the subjects for the entire research process in this study. All specimens were anonymized and handled according to the aforementioned ethical and legal standards.

Cells and animals. The mouse myeloma cell line SP2/0-Ag14 was obtained from the American Type Culture Collection (cat.no.CRL-1581; Manassas, VA, USA). Specific pathogen-free female BALB/c mice (weight, 18-20 g; age, 6-7 weeks) were purchased from Charles River Laboratories (Saint Constant, QC, Canada). Procedures involving animals and their care were conducted at Yes Biotech Laboratories registered animal facility (license no. 0107-01; Yes Biotech Laboratories Ltd., Mississauga, ON, Canada) under the Animals for Research Act and at the supervision of Ontario Ministry of Agriculture, Food and Rural Affairs (Guelph, ON, Canada). The mice were maintained at $20-23^{\circ} \mathrm{C}$, with a humidity of $40-60 \%$ and exposed to $12 \mathrm{~h} / 12 \mathrm{~h}$ light-dark cycles. Mice were fed on Laboratory Rodent Diet 5001 purchased from Ren's Pets Depot (Oakville, ON, Canada). The procedures and pain level assessments were reviewed and approved by Yes Biotech Laboratories Animal Care Committee and complied with the Animals for Research Act.

Chemicals and reagents. Freund's complete adjuvant and Freund's incomplete adjuvant solutions were purchased from Sigma-Aldrich; Merck KGaA (Darmstadt, Germany). Incomplete medium used for hybridoma development consisted of base medium and supplements purchased from Gibco; Thermo Fisher Scientific, Inc. (Waltham, MA, USA). The incomplete medium contained 50\% RPMI-1640 (cat. no. 11875-093), 50\% Dulbecco's modified Eagle's medium/F12 (cat. no. 11320-033), 1\% L-glutamine (200 mM; cat. no. 15039-027), 1\% minimum essential medium-non essential amino acids (cat. no. 11140-050), 0.1\% mercapotoethanol (cat. no. 21985-023), and 1\% Antibiotic-Antimycotic (cat. no. 15240-062). Complete medium consisted of incomplete medium supplemented with $10 \%$ fetal bovine serum (cat. no. 10091-148; Gibco, Thermo Fisher Scientific, Inc.). Polyethylene glycol 1500 [PEG 1500; 50\% (w/v)] was purchased from Roche Diagnostics (Lavel, QC, Canada). Recombinant Human PD-1/PDCD1 protein was purchased from ACROBiosystems (Newark, DE, USA). Control mouse anti-PD-1 monoclonal antibody (clone ID: UMAB199), horseradish peroxidase (HRP)-conjugated goat anti-mouse IgG (cat. no. ZB-2305) and diaminobenzidine (DAB) were purchased from OriGene Technologies, Inc. (Beijing, China). Normal goat serum and neutral gum were purchased from Wuhan Boster Biological Technology, Ltd. (Wuhan, China). 4-chloro-1-naphthol substrate (cat. no. C8890) was purchased from Sigma-Aldrich; Merck KGaA. The Mouse Typer Sub-Isotyping kit was purchased from Bio-Rad Laboratories, Inc. (Hercules, CA, USA).

Preparation of $m A b s$. The mAbs were prepared by Yes Biotech Laboratories Ltd. A total of 4 BALB/c mice were used for this project. The mice were divided into two equal groups, and were immunized using the same procedure. The first immunization was performed subcutaneously at multiple sites on the back of each mouse with $200 \mu \mathrm{l}$ emulsion consisting of phosphate-buffered saline (PBS) containing $25 \mu \mathrm{g}$ recombinant PD-1 protein (cat. no. PD1-H5221; ACROBiosystems) and $100 \mu$ l complete Freund's adjuvant solution. The immunization was boosted twice intraperitoneally (IP) with an emulsion containing $25 \mu \mathrm{g}$ PD-1 protein and $100 \mu \mathrm{l}$ incomplete Freund's adjuvant at 3-week intervals. At 10 days following the second booster injection, $4 \mu \mathrm{l}$ blood was collected from the tip of the mouse tail. The antibody titers in the serum were assessed by indirect ELISA method using the recombinant PD-1 (immunogen)coated ELISA plates (developed in-house by Yes Biotech Laboratories Ltd.). The negative control in the indirect ELISA was PBS, which was the diluent for the mouse serum samples. The blank control was substrate reading. A final booster injection was performed with $25 \mu \mathrm{g}$ PD-1 protein in $50 \mu \mathrm{l}$ PBS (IP). At 4 days following the final booster injection, the mice with the desired antibody titer $\left(>10^{6}\right)$ were sacrificed by cervical dislocation by a trained animal technician. The spleen was 
removed and spleen cells were isolated. A total of $10^{8}$ cells were obtained from each spleen of the immunized mice. The spleen cells were mixed with the Sp2/0-Ag14 myeloma cells, which were pre-selected with 8-azaguanine (cat. no. A5284; Sigma-Aldrich; Merck KGaA) for fusion in a sterile centrifuge tube in the presence of 50\% PEG 1500 (cat. no. 783641; Roche Applied Science), as previously described $(31,32)$. At $24 \mathrm{~h}$ following fusion, the hybridomas were selected by adding $100 \mu \mathrm{l}$ of complete medium supplemented with $1 \%$ hypoxanthine-aminopterin-thymidine (cat. no. 31062-011; Gibco; Thermo Fisher Scientific, Inc.) to each well. At 8 days following fusion, the supernatants were tested for PD-1 antibody by indirect ELISA method using the recombinant PD-1 (immunogen)-coated plates. Cells whose supernatants exhibiting strong reactivity with immunogen in the indirect ELISA were subcloned by a limiting dilution procedure in complete medium supplemented with $1 \%$ hypoxanthine-thymidine (cat. no. 11067-030; Gibco; Thermo Fisher Scientific, Inc.).

Isotyping and antibody purification. The $\mathrm{mAb}$ isotypes secreted by the hybridomas were determined using the Mouse Typer Sub-Isotyping kit (cat. no. 1722051; Bio-Rad Laboratories, Inc.) according to the manufacturer's instructions. This ELISA-based kit uses a panel of ultrapure reagents to determine the mouse sub-isotypes IgG1, IgG2a, IgG2b, IgG3, $\operatorname{IgM}, \operatorname{Ig} \mathrm{A}, \kappa$ and $\lambda$ chains. In the experiment, PD- 1 was coated onto an ELISA microplate, and then each specific anti-PD-1 monoclonal antibody was added to the respective columns. The isotype antibodies were added to respective horizontal rows. Immunoglobulin isotypes were then determined using goat anti-rabbit $(\mathrm{H}+\mathrm{L}) \mathrm{HRP}$ conjugate (dilution, 1:2,000; cat. no. 172-1019; Bio-Rad Laboratories, Inc.) and 3,3',5,5'-tetramethylbenzidine substrate (cat. no. 00-4201-56; Thermo Fisher Scientific, Inc.). Subsequently, the mAbs were purified using GammaBind Plus sepharose resin (cat. no. 17088602; GE Healthcare Life Sciences, Little Chalfont, UK).

Measurement of $m A b$ specificity by western blot analysis. A $15 \%$ PAGE gel was prepared and SDS-PAGE was performed as described previously (33) using recombinant PD-1 protein (cat. no. PD1-H5221; ACROBiosystems) following denaturation for $10 \mathrm{~min}$ at $100^{\circ} \mathrm{C}$. The PD-1 protein was loaded at $40 \mathrm{ng} /$ lane. Following electrophoresis, the protein was transferred to polyvinylidene difluoride membranes (Merck KGaA) at $150 \mathrm{~mA}$ for $2 \mathrm{~h}$ in transfer buffer at $4^{\circ} \mathrm{C}$. The membranes were washed five times with PBS containing $0.05 \%$ Tween -20 (PBST), and blocked with 3\% gelatin in PBS at room temperature for $2 \mathrm{~h}$. The membranes were subsequently cut into strips along the lane dividers. Each of the 14 prepared PD-1 antibodies were quantified with a spectrophotometer by measuring the absorbance of the antibody samples at $280 \mathrm{~nm}$. The antibodies were then diluted to $1 \mu \mathrm{g} / \mathrm{ml}$ in PBST, and incubated with individual strips at room temperature for $2 \mathrm{~h}$. Following five washes with PBST, the strips were incubated with HRP-conjugated goat anti-mouse IgG (Yes Biotech Laboratories Ltd.) diluted to 1:1,000 in PBST with 1\% bovine serum albumin (cat. no. 81-003-07; Merck KGaA) for $1 \mathrm{~h}$ at room temperature. The strips were then washed five times with PBST. The $40-\mathrm{kD}$ PD-1 bands were visualized by incubating the membranes with 4-chloro-1-naphthol substrate (cat. no. C8890; Sigma-Aldrich; Merck KGaA).

Measurement of $m A b$ specificity for PD-1 in HCC specimens by IHC staining. The paraffin-embedded tissues specimens collected from HCC patients were prepared and stored by the Pathology Department of the Daping Hospital Third Military Medical University. The $3-\mu$ m-thick tissue sections were dewaxed in xylene, rehydrated in alcohol and immersed in $3 \%$ hydrogen peroxide for $10 \mathrm{~min}$ at room temperature to suppress endogenous peroxidase activity. Antigen retrieval was performed by heating each section for $30 \mathrm{~min}$ in $0.01 \mathrm{~mol} / 1$ sodium citrate buffer $(\mathrm{pH} 6.0)$ at $100^{\circ} \mathrm{C}$. Sections were then washed three times in PBS (each for 5 min). After blocking any nonspecific binding with ready-to-use normal goat serum for $30 \mathrm{~min}$ at $37^{\circ} \mathrm{C}$, the sections were incubated in a humidified chamber overnight at $4^{\circ} \mathrm{C}$ with each of the 14 prepared PD-1 mAbs (diluted, 1:400). The commercial anti-PD-1 mAb (dilution, 1:400; cat. no. UMAB199) was used as the positive control, while PBS was used as the negative control. The sections were then incubated with HRP-conjugated goat anti-mouse IgG (diluted, 1:500; cat. no.ZB-2305; OriGene Technologies, Inc.) for $30 \mathrm{~min}$ at room temperature. Following three additional washes, peroxidase activity was developed with DAB for $5 \mathrm{~min}$ at room temperature. The sections were counterstained with $0.2 \%$ hematoxylin for $1 \mathrm{~min}$ at room temperature. The optical density of the sections was quantitatively analyzed using Image-Pro Plus 6.0 software (Media Cybernetics, Inc., Rockville, MD, USA).

Assessing the correlation between PD-1 expression and clinical significance in HCC. The paraffin-embedded HCC tissues were stained with $0.2 \%$ hematoxylin for $5 \mathrm{~min}$ and counterstained with $0.5 \%$ eosin for $1 \mathrm{~min}$ at room temperature to identify the cancer tissues and the adjacent normal regions. According to the results of the mAb analyses, the highest-specificity PD-1 $\mathrm{mAb}(9 \mathrm{E} 11)$ was selected to detect the expression of PD-1 in $\mathrm{HCC}$ tissues, in order to assess the correlation between the expression of PD-1 in the tumor tissues and the clinicopathological features of patients, and to evaluate the feasibility of utilizing an anti-PD-1 mAb in the treatment of HCC. The IHC methods used were the same as those described above.

Two experienced pathologists evaluated tissue staining intensity and positive cell percentage scoring in a double-blind manner $(34,35)$. A total of five $\mathrm{T}$ lymphocyte infiltrationdense regions were selected for counting the number of PD- $1^{+}$ $\mathrm{T}$ lymphocytes in each tissue section. The expression levels of PD-1 were defined by a 'quickscore', which was calculated according to the methods described previously $(34,35)$. Briefly, the proportion of positively stained cells throughout the section was termed category $\mathrm{A}$, and was assigned a score ranging from 0 to $3(0,0-4 \%$; $1,5-24 \% ; 2,25-49 \% ; 3,50-100 \%)$. The entire section was scanned at low microscopic power in order to gauge the levels of staining intensity. The average intensity defined as negative (colorless), weak (pale yellow), intermediate (pale brown), or strong staining (dark brown) was assigned a score ranging from 0 to 3 , and termed category $\mathrm{B}$. The product $(\mathrm{A}+\mathrm{B})$ was recorded as the total score. Total scores $<3$ were considered to indicate negative PD-1 expression, while total scores $\geq 3$ were considered to indicate positive PD-1 expression. 
Table I. Antibody titers in the sera of the immunized mice.

\begin{tabular}{lllllllll}
\hline Group & $1: 10^{3}$ & $1: 10^{4}$ & $1: 10^{5}$ & $1: 10^{6}$ & $1: 10^{7}$ & $1: 10^{8}$ & Negative control & Blank control \\
\hline 1 & 2.642 & 1.722 & 0.699 & 0.386 & 0.201 & 0.063 & 0.052 & 0.040 \\
2 & 2.944 & 2.327 & 0.973 & 0.332 & 0.148 & 0.090 & 0.041 & 0.039 \\
\hline
\end{tabular}

Table II. Isotype determination of mouse anti-human programmed cell death-1 mAb.

\begin{tabular}{|c|c|c|c|c|c|c|c|c|c|c|c|c|c|c|}
\hline \multirow[b]{2}{*}{ Subtype } & \multicolumn{14}{|c|}{ mAb clone } \\
\hline & IC4 & $1 \mathrm{H} 8$ & $2 \mathrm{C} 4$ & $2 \mathrm{H} 7$ & $3 \mathrm{E} 5$ & $5 \mathrm{~B} 2$ & $5 \mathrm{H} 7$ & 7C9 & $7 \mathrm{E} 5$ & $7 \mathrm{G} 12$ & $9 \mathrm{~A} 5$ & 9B4 & 9E11 & $\mathrm{B} 1 \mathrm{C} 4$ \\
\hline IgG1 & 2.91 & 2.85 & 2.49 & 1.82 & 2.56 & 1.96 & 2.23 & 2.89 & 2.08 & 2.15 & 0.08 & 2.02 & 2.02 & 2.45 \\
\hline $\operatorname{IgG} 2 \mathrm{a}$ & 0.99 & 0.47 & 0.21 & 0.13 & 0.14 & 0.31 & 0.18 & 0.23 & 0.11 & 0.16 & 1.49 & 0.21 & 0.20 & 0.22 \\
\hline $\operatorname{IgG} 2 b$ & 0.82 & 0.15 & 0.08 & 0.08 & 0.04 & 0.20 & 0.06 & 0.17 & 0.05 & 0.05 & 0.08 & 0.08 & 0.06 & 0.09 \\
\hline IgG3 & 0.62 & 0.13 & 0.05 & 0.12 & 0.12 & 0.19 & 0.05 & 0.15 & 0.04 & 0.04 & 0.04 & 0.06 & 0.05 & 0.05 \\
\hline IgM & 0.12 & 0.20 & 0.11 & 0.17 & 0.06 & 0.27 & 0.06 & 0.17 & 0.05 & 0.11 & 0.05 & 0.06 & 0.14 & 0.11 \\
\hline $\operatorname{IgA}$ & 0.05 & 0.09 & 0.06 & 0.16 & 0.06 & 0.21 & 0.04 & 0.05 & 0.04 & 0.04 & 0.05 & 0.04 & 0.05 & 0.05 \\
\hline$\kappa$ & 2.56 & 2.77 & 2.02 & 1.57 & 1.86 & 1.82 & 1.84 & 2.62 & 1.46 & 1.71 & 0.97 & 1.95 & 1.90 & 2.00 \\
\hline$\lambda$ & 0.09 & 0.13 & 0.07 & 0.09 & 0.06 & 0.19 & 0.11 & 0.08 & 0.05 & 0.05 & 0.07 & 0.01 & 0.05 & 0.07 \\
\hline
\end{tabular}

mAb, monoclonal antibody.

In addition to the aforementioned methods, the number of positive cells per field of view was evaluated under a high-powered microscope by two experienced pathologists as described previously (36). A total of five T lymphocyte infiltration-dense regions (at x200 magnification) were selected for counting the number of PD-1 positive cells in each tissue section. PD-1 expression levels in HCC tissues were determined by calculating the number of PD-1 ${ }^{+} \mathrm{T}$ lymphocytes per field of view.

Statistical analysis. IBM SPSS Statistics software (version 23.0; IBM Corp., Armonk, NY, USA) was used for statistical analysis. The results were expressed as the mean \pm standard deviation. Differences among multiple groups were compared by one-way analysis of variance followed by the Games-Howell post hoc test. The $\chi^{2}$ and Fisher's exact test were used for the comparison of categorical variables. The Mann-Whitney U test was applied for the comparison of ranked data. The evaluation of multiple factors was performed by stepwise binary logistic regression. $\mathrm{P}<0.05$ was considered to indicate statistically significant difference.

\section{Results}

Immunized BALB/c mice meet the requirements of cell fusion experiments. The recombinant human $\mathrm{PD}-1 / \mathrm{PDCD} 1$ protein was used as antigen to immunize BALB/c mice. Blood was collected from the mice tail tips at 10 days following the final booster injection, and the antibody titers in the serum were assessed by indirect ELISA. As shown in Table I, serum antibody titers reached $1: 10^{7}$, and the desired immunization effect was therefore achieved for subsequent cell fusion experiments.

Successful production of 14 specific PD-1 mAbs. Splenocytes from the immunized BALB/c mice were fused with the mouse myeloma cell line Sp2/0-Ag14. PD-1 mAbs were generated and assigned the following names: $1 \mathrm{C} 4,1 \mathrm{H} 8,2 \mathrm{C} 4,2 \mathrm{H} 7$, 3E5, 5B2, 5H7, 7C9, 7E5, 7G12, 9A5, 9B4, 9E11 and B1C4. Following repeated serial culture in vitro, cryopreservation and revival, the hybridomas maintained a normal morphology and continuously secreted PD-1 mAbs (data not shown).

Identification of the mAb isotypes. The isotypes of the $14 \mathrm{mAbs}$ were determined using a Mouse Typer Sub-Isotyping kit. As shown in Table II, the heavy chains of 13 mAbs were IgG1, while clone 9A5 was observed to be IgG2a. All 14 mAbs were observed to contain $\kappa$ light chains.

Specificity of PD-1 mAbs for antigen recognition as determined by western blot analysis. The $14 \mathrm{mAbs}$ were used as primary antibodies in western blot analysis to detect PD-1 protein. The molecular weight of recombinant human $\mathrm{PD}-1 / \mathrm{PDCD} 1$ protein is $40 \mathrm{kDa}$. As shown in Fig. 1, the 2C4, 5B2, 5H7, 7E5, 7G12, 9A5, 9B4, 9E11 and B1C4 mAbs demonstrated a high specificity for PD-1, indicating that these antibodies may be used as detection antibodies in western blotting. By contrast, a weak reaction was observed for $1 \mathrm{C} 4$ and $2 \mathrm{H} 7 \mathrm{mAbs}$, and no reaction was observed for the 7C9, $1 \mathrm{H} 8$ and 3E5 mAbs. This indicates that these five mAbs are unsuitable for the detection of PD-1 by western blot analysis. However, it remains unclear whether they would be useful for the additional immunostaining experiments, such as IHC analysis.

PD-1 mAb $9 E 11$ exhibited the strongest specificity for antigen recognition in HCC tissues by IHC analysis. The 14 mouse anti-human PD-1 mAbs were used for IHC analysis of HCC tissues as primary antibodies. As shown in Fig. 2, the 9E11 and $2 \mathrm{H} 7 \mathrm{mAbs}$ exhibited strong positive staining, particularly 


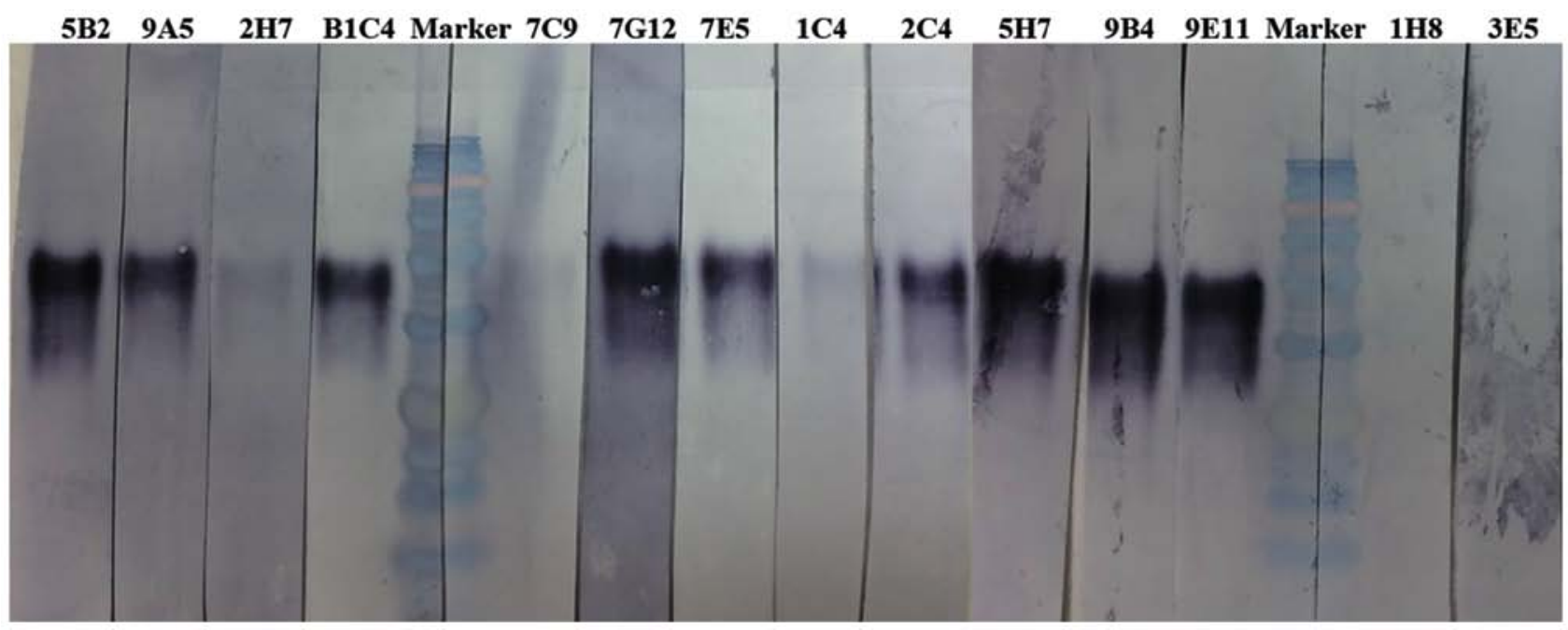

Figure 1. Specificity of mouse anti-human PD-1 mAbs by western blot analysis. The recombinant PD-1 protein (40 kDa) was subjected to SDS-PAGE and blotted with the 1C4, 1H8, 2C4, 2H7, 3E5, 5B2, 5H7, 7C9, 7E5, 7G12, 9A5, 9B4, 9E11 and B1C4 mAb clones. PD-1, programmed cell death-1; mAb, monoclonal antibody.

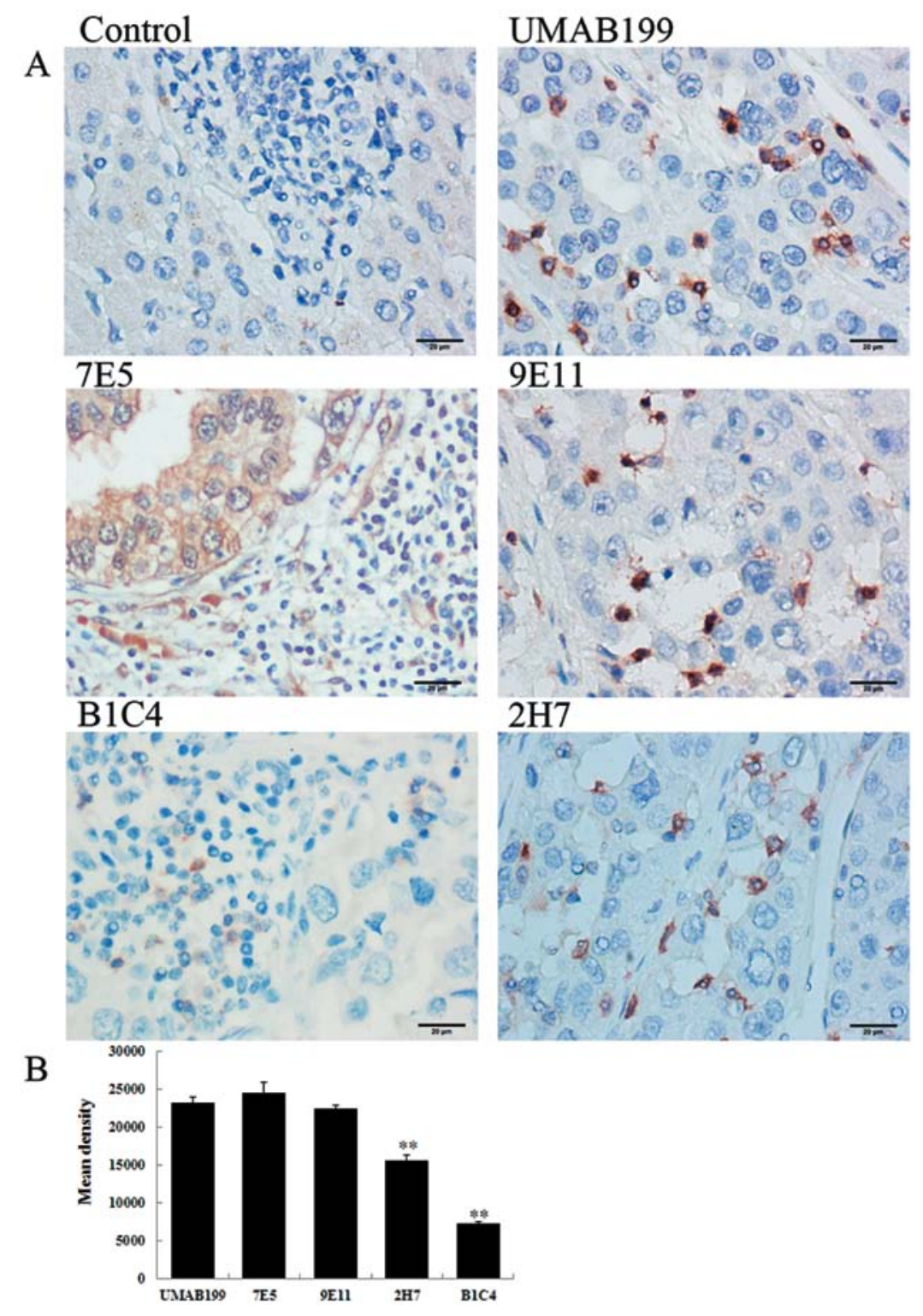

Figure 2. Specificity of mouse anti-human PD-1 mAbs by immunohistochemical staining. (A) Representative immunohistochemical staining images of hepatocellular carcinoma tissue sections (magnification, $\mathrm{x} 400$ ). (B) Mean optical densities of the positively stained specimens. ${ }^{* *} \mathrm{P}<0.001$ vs. UMAB199. PD-1, programmed cell death-1. 

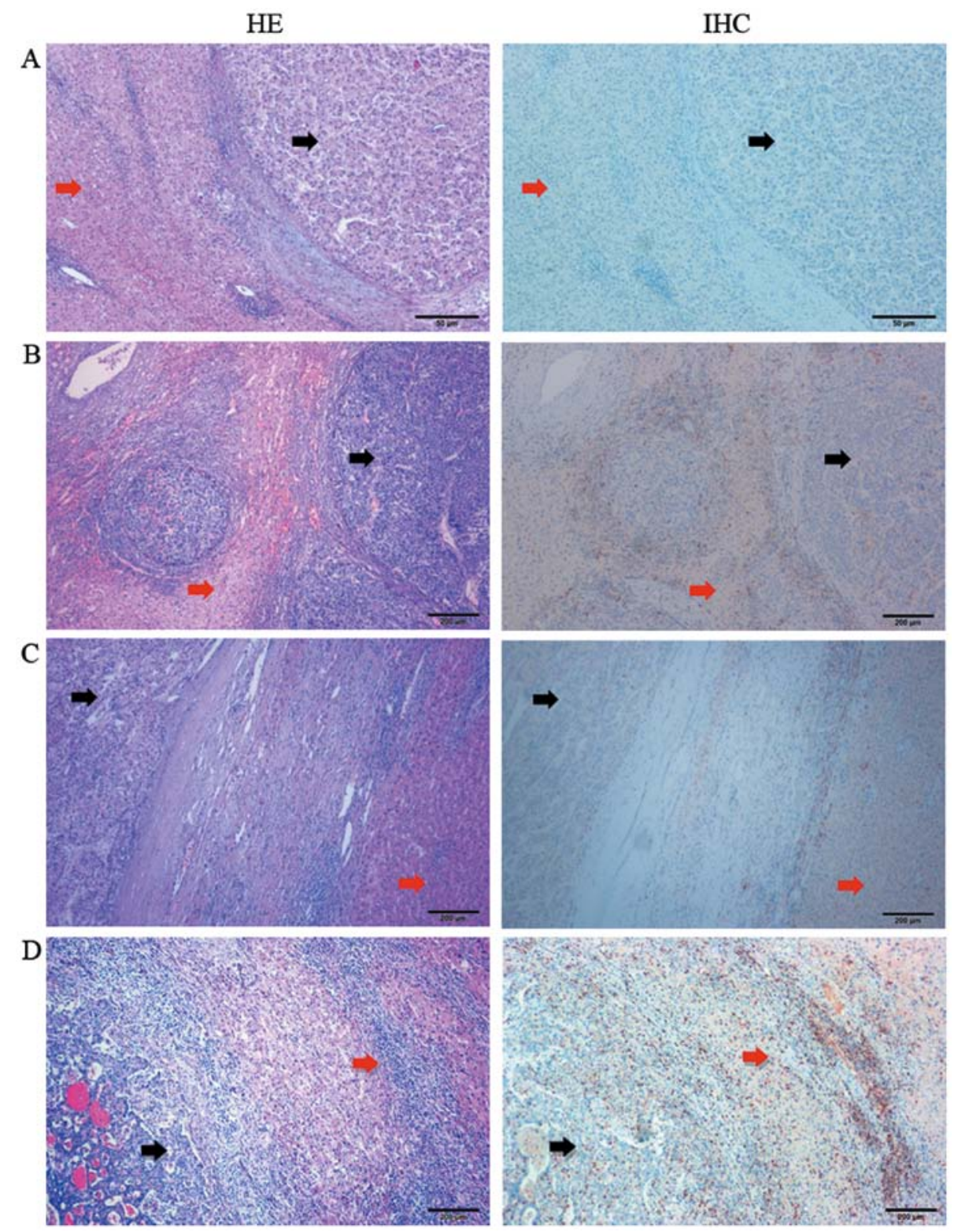

Figure 3. Location of PD-1+ $\mathrm{T}$ lymphocytes in hepatocellular carcinoma tissues. Representative microscope images showing the (A) tumor interior, (B) nodular margin of the tumor, (C) tumor-normal adjacent tissue junction and the (D) liver tissue surrounding the tumor. Black arrows indicate tumor tissues, and red arrows indicate peritumoral tissues (magnification, x40). PD-1, programmed cell death-1.

the 9E11 clone, which was similar to the commercial antibody UMAB199 in detecting PD-1 expression (Fig. 2B). Using the $9 \mathrm{E} 11 \mathrm{mAb}$, the staining was dark, the background of tissues was clear and there was non-specific staining. By contrast, the $\mathrm{B} 1 \mathrm{C} 4 \mathrm{mAb}$ exhibited lighter staining when compared with the UMAB199 positive control. The remaining $11 \mathrm{mAbs}$ exhibited more non-specific staining, as demonstrated by the staining pattern observed when the 7E5 mAb was used (Fig. 2); the antibody bound to additional non-specific proteins on tumor cell membranes. The results indicated that these mAbs demonstrate poor specificity for PD-1 in HCC tissues. Therefore, the $9 \mathrm{E} 11 \mathrm{mAb}$, which exhibited the strongest specificity for PD-1, was used to investigate the clinical significance of PD-1 expression in $\mathrm{HCC}$ tissues for subsequent experiments.

$P D-1$ is highly expressed in the peritumoral tissues at the junction of tumors. A total of 77 HCC tumor specimens were examined by IHC. The distribution of PD-1 expression in the HCC tissue samples is presented in Figs. 3 and 4. The images in Fig. 3 display HE and IHC staining results where the same HCC tissue sections were stained in tandem. The tumor tissues (black arrows) and peritumoral tissues (red arrows) were clearly distinguished by comparing the HE and IHC images of the same HCC tissue section. A large number of $\mathrm{T}$ lymphocytes were identified in the peritumoral tissues at the tumor-normal adjacent tissue junction. The distribution of PD- $1^{+} \mathrm{T}$ lymphocytes at different HCC tissue locations, as detected by IHC, is presented in Fig. 4. An accumulation of a small number of PD-1 $1^{+} \mathrm{T}$ lymphocytes was observed in the nodular margin of the HCC tissue (Fig. 4A). A large number of $\mathrm{T}$ lymphocytes were present in the peritumoral tissues at tumor-normal adjacent tissue junction (Fig. 4B and C) and primarily in the liver portal region (Fig. 4B). In addition, due to the low degree of $\mathrm{T}$ lymphocyte infiltration in the tumor 

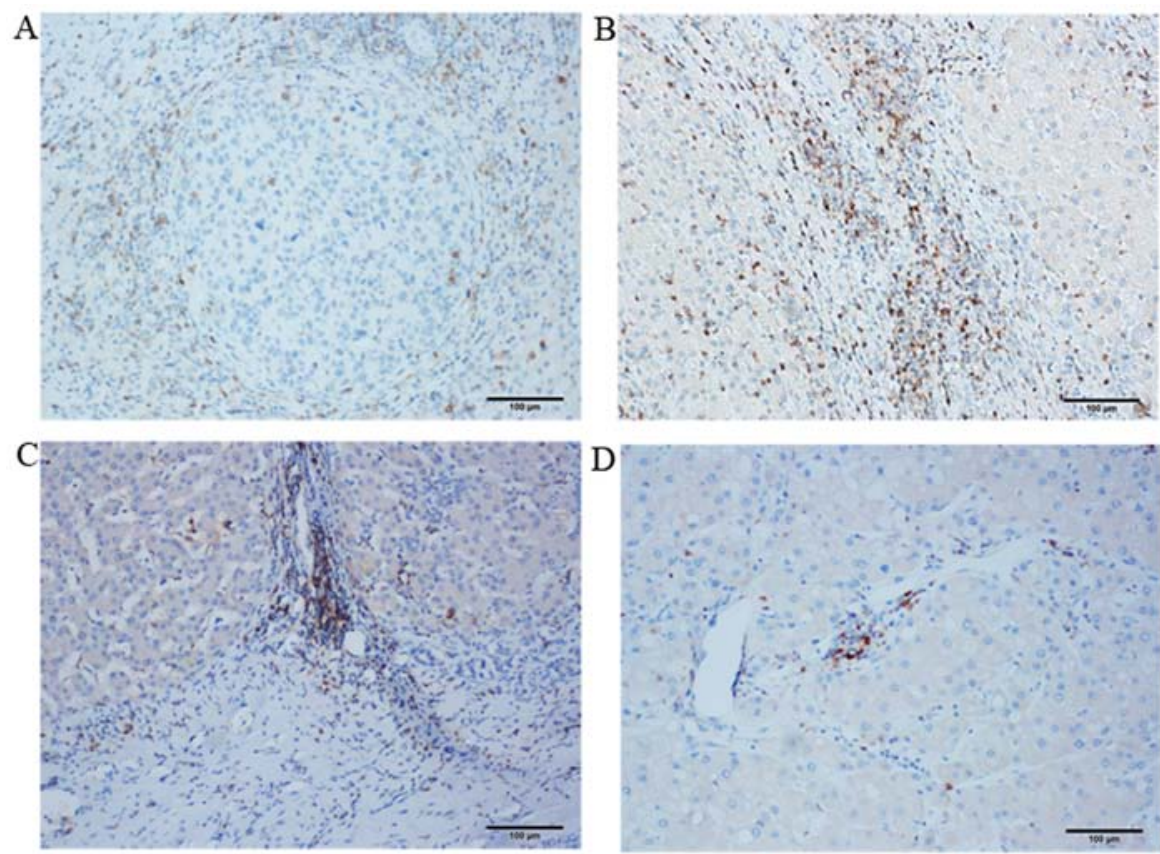

Figure 4. Location of PD-1+ $\mathrm{T}$ lymphocytes in different hepatocellular carcinoma tissue regions as detected by immunohistochemical staining. Representative microscope images of the (A) nodular margin of the tumor, (B) liver tissue surrounding the tumor, (C) tumor-normal adjacent tissue junction and (D) tumor interior (magnification, x100). PD-1, programmed cell death-1.
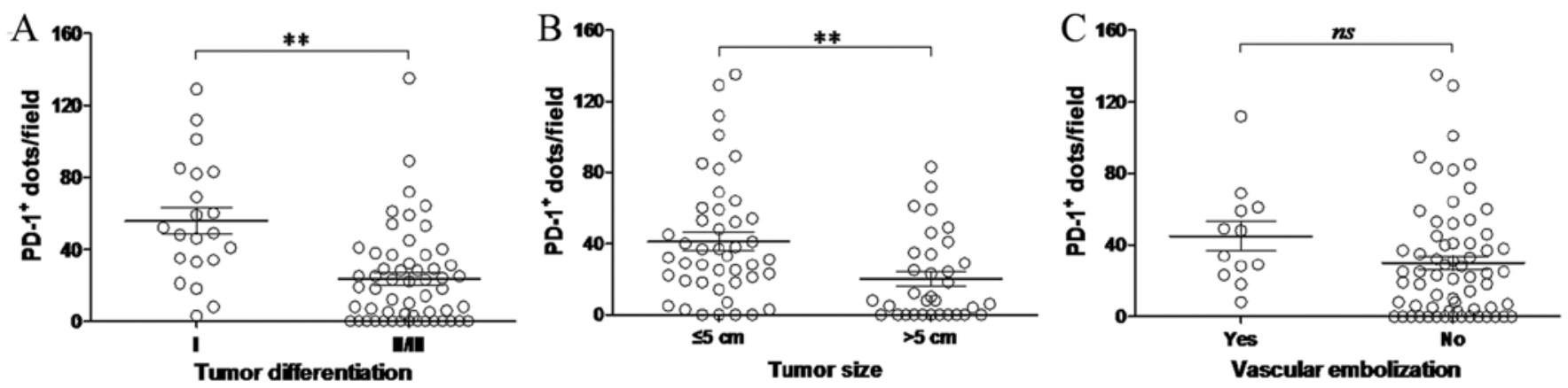

Figure 5. Expression of PD-1 in hepatocellular carcinoma tissues and the clinicopathological characteristics of patients based on the number of PD-1 ${ }^{+}$lymphocytes per field of view. The number of PD-1 $1^{+} \mathrm{T}$ lymphocytes in patients grouped by (A) degree of tumor differentiation, (B) tumor size and (C) the presence of vascular tumor emboli. The data were collected at X200 magnification by two different investigators. Each dot represents the number of PD-1+ lymphocytes per field of view in one tissue section from each patient. Black bars indicate the mean \pm standard deviation. ${ }^{* *} \mathrm{P}<0.01$, as indicated. PD- 1 , programmed cell death-1; ns, not significant.

interior, fewer PD-1+ $\mathrm{T}$ lymphocytes were observed in this region (Fig. 4D). Therefore, peritumoral tissues at the tumornormal adjacent tissue junction were selected to analyze the correlation between PD-1 expression in HCC and the clinical and pathological characteristics of patients.

PD-1 expression level in HCC tissues is closely associated with tumor size and the degree of differentiation. Under a double-blind setting, the results of IHC analysis for the 77 HCC cases (Table III) were evaluated by two pathologists according to the staining intensity of PD-1 combined with the ratio of PD-1-positive cells. Using these results, the correlation between PD-1 expression in the HCC tissues and the clinical and pathological characteristics of patients were statistically evaluated. As demonstrated in Table IV, PD-1 expression in HCC tissues was significantly associated with tumor size, venous thrombosis and the degree of tumor differentiation. The rate of positive PD-1 expression in $\mathrm{HCC}$ cases with a tumor size $\leq 5 \mathrm{~cm}$ was higher than that in tumors $>5 \mathrm{~cm}$ in size $(\mathrm{P}<0.01)$. The proportion of HCC tissue samples derived from patients with venous thrombosis that were positive for PD-1 expression was higher than in the proportion of patients positive for PD-1 expression without venous thrombosis $(\mathrm{P}<0.05)$. In addition, the positive rate of PD-1 in poorly differentiated (highly malignant) HCC was significantly higher than in moderately and highly differentiated HCC $(\mathrm{P}<0.01)$. The expression of PD-1 in HCC tissues was not correlated with patient sex, median age, hepatic cirrhosis, hepatitis B infection, TNM stage or tumor location (Table IV).

The number of PD-1 positive cells in multiple fields of view (x200 magnification) for each tissue section was then determined (Fig. 5). The number of PD-1+ $\mathrm{T}$ lymphocytes was closely correlated with tumor size and differentiation $(\mathrm{P}<0.01$; 


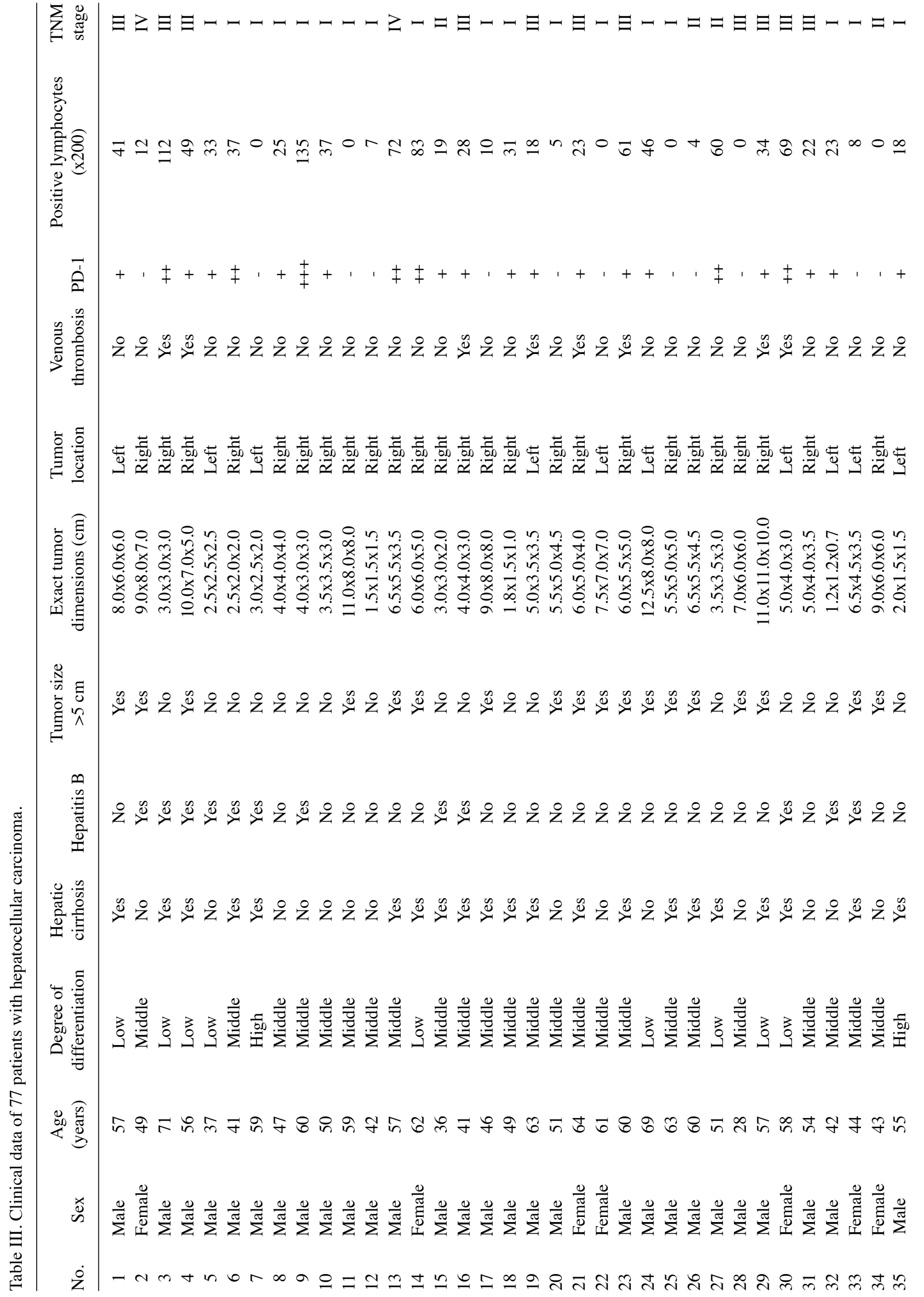




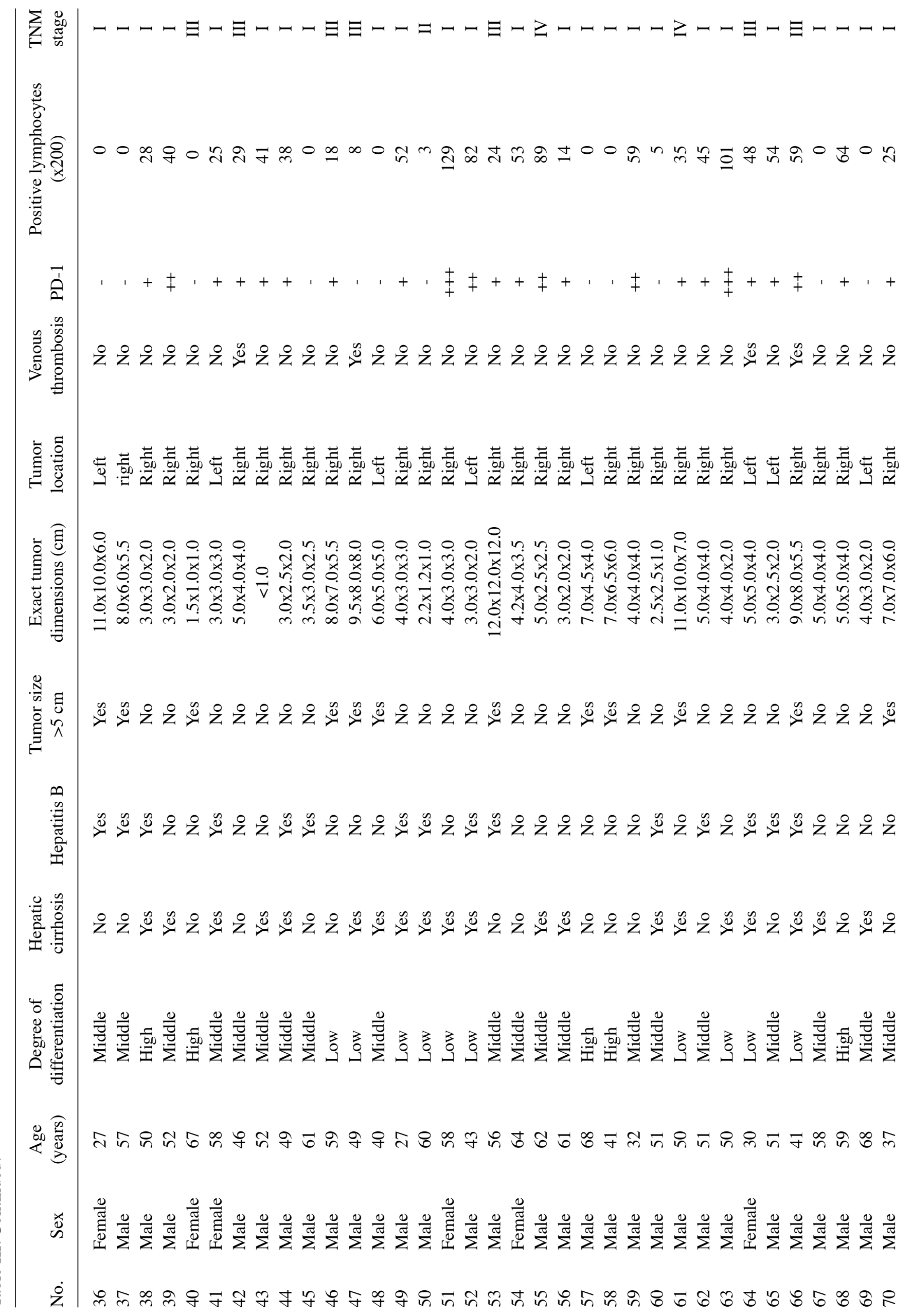




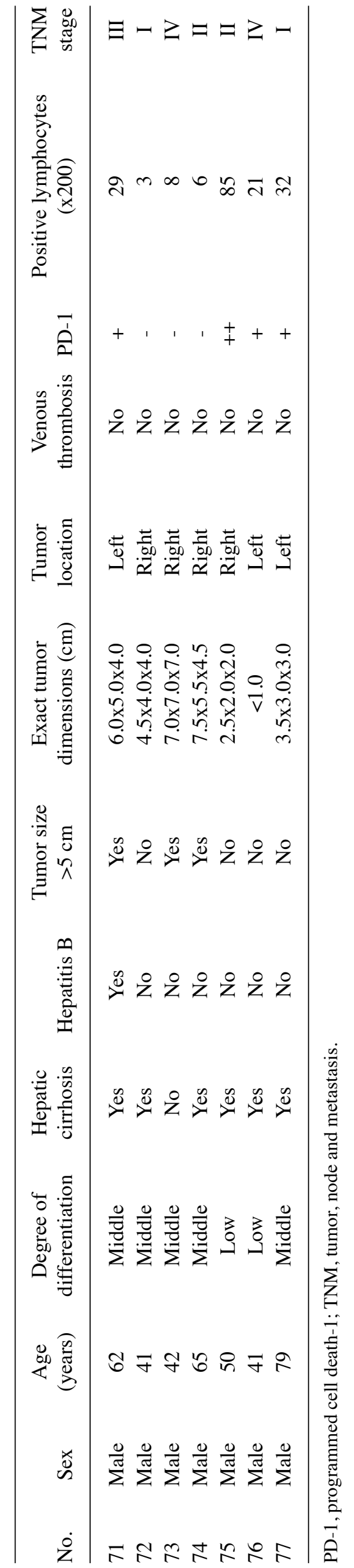

Table IV.Association between PD-1 expression in hepatocellular carcinoma tissues and the clinicopathological characteristics of patients based on the staining intensity combined with the ratio of PD- $1^{+}$lymphocytes.

\begin{tabular}{|c|c|c|c|c|}
\hline \multirow[b]{2}{*}{ Variable } & \multicolumn{4}{|c|}{ PD-1 expression } \\
\hline & No. & Positive & Negative & P-value \\
\hline \multicolumn{5}{|l|}{ Sex } \\
\hline Male & 64 & 43 & 21 & 0.358 \\
\hline Female & 13 & 7 & 6 & \\
\hline \multicolumn{5}{|c|}{ Age (years) } \\
\hline$\leq 52$ & 40 & 26 & 14 & 0.990 \\
\hline$>52$ & 37 & 24 & 13 & \\
\hline \multicolumn{5}{|c|}{ Tumor size $(\mathrm{cm})$} \\
\hline$\leq 5$ & 44 & 36 & 8 & $<0.001$ \\
\hline$>5$ & 33 & 14 & 19 & \\
\hline \multicolumn{5}{|c|}{ Hepatic cirrhosis } \\
\hline Yes & 47 & 34 & 13 & 0.088 \\
\hline No & 30 & 16 & 14 & \\
\hline \multicolumn{5}{|c|}{ Hepatitis B } \\
\hline Yes & 28 & 20 & 8 & 0.367 \\
\hline No & 49 & 30 & 19 & \\
\hline \multicolumn{5}{|c|}{ Venous thrombosis } \\
\hline Yes & 12 & 11 & 1 & 0.035 \\
\hline No & 65 & 39 & 26 & \\
\hline \multicolumn{5}{|c|}{$\begin{array}{l}\text { Degree of } \\
\text { differentiation }\end{array}$} \\
\hline I & 21 & 19 & 2 & 0.004 \\
\hline II/III & 56 & 31 & 25 & \\
\hline \multicolumn{5}{|c|}{ TNM stage } \\
\hline I & 45 & 27 & 18 & 0.181 \\
\hline II & 6 & 3 & 3 & \\
\hline III & 20 & 16 & 4 & \\
\hline IV & 6 & 4 & 2 & \\
\hline \multicolumn{5}{|c|}{ Tumor location } \\
\hline Right & 56 & 36 & 20 & 0.845 \\
\hline Left & 21 & 14 & 7 & \\
\hline
\end{tabular}

PD-1, programmed cell death-1; TNM, tumor, node and metastasis.

Fig. 5A and B). PD-1 expression was significantly increased in tumors $\leq 5 \mathrm{~cm}$ in size or in poorly differentiated tumors, which is consistent with the aforementioned IHC results. By contrast, no correlation between the number of $\mathrm{PD}-1^{+} \mathrm{T}$ lymphocytes in HCC tissues and the presence of venous thrombosis was observed (Fig. 5C).

The results indicate that PD-1 expression in HCC tissues may be closely correlated with tumor size and the degree of differentiation and moderately correlated with venous thrombosis. However, PD-1 expression does not appear to be correlated with additional clinical characteristics, including patient sex, age, cirrhosis, hepatitis B infection, TNM stage or tumor location. 


\section{Discussion}

Tumor cells are able to escape clearance by the host immune system through a variety of mechanisms; one of which is the PD-1/PD-L1 immune checkpoint that serves a crucial role in this process (37). Tumor cells recognize PD-1 proteins, which are expressed on effector $\mathrm{T}$ cells, by overexpressing PD-L1. Activation of the PD-1/PD-L1 immune checkpoint subsequently communicates immunosuppressive signals to $\mathrm{T}$ cells, leading to evasion of tumor cell clearance by the host immune system (6-8). Therefore, inhibition of the PD-1/PD-L1 immune checkpoint has been widely investigated as a promising strategy for antitumor immunotherapy, in an attempt to reverse the immunological tolerance of tumor cells in the host.

Inhibitory antibodies targeting the PD-1/PD-L1 immune checkpoint have demonstrated substantial clinical effects in patients with metastatic melanoma, renal cell carcinoma, non-small cell lung cancer and a number of additional tumors $(6,8,9)$. However, reports concerning the curative effects of these antibodies in patients with HCC are limited. It has been generally recognized that $\mathrm{HCC}$ is a life-threatening malignancy with high mortality rates and now ranks as the second cause of cancer-associated death worldwide. This is particularly the case in China, where the number of HCC cases accounts for $42.5 \%$ of the total number of global cases (38). This indicates the broad potential application of PD-1/PD-L1 immune checkpoint inhibitors in HCC immunotherapy (17-20). Therefore, the development of novel anti-PD-1 mAbs may be of great significance for the immunotherapeutic treatment and diagnosis of HCC.

In the present study, the $9 \mathrm{E} 11 \mathrm{mAb}$ clone, which demonstrated the highest specificity for PD-1 in HCC tissues, was used to investigate PD-1 expression in HCC tissues by IHC. In HCC tissues, PD-1 $1^{+} \mathrm{T}$ lymphocytes were primarily located in the peritumoral tissues at the tumor-normal adjacent tissue junction, while relatively few PD- $1^{+} \mathrm{T}$ lymphocytes were identified in the tumor interior. In addition, although the number of infiltrating $\mathrm{T}$ lymphocytes in the tumor interior was small, the proportion of PD-1+ $\mathrm{T}$ lymphocytes out of the total number of infiltrating $\mathrm{T}$ lymphocytes was large and not significantly different from that in the peritumoral tissues. The characteristics of PD-1 expression and distribution in the HCC tissues were similar to those reported in the literature (39-41). Shen et al (42) reported that the proportion of PD- $1^{+} \mathrm{CD}^{+}$ $\mathrm{T}$ lymphocytes in HCC tumors was significantly higher when compared with adjacent tissues. An additional previous study demonstrated that the expression level of PD-1 on CD8 ${ }^{+}$ tumor infiltrating lymphocytes was significantly higher when compared with non-tumor infiltrating lymphocytes (43).

In the present study, two methods were employed to evaluate and analyze the results of IHC analysis. In a previous report, Chang et al (44) demonstrated that high PD-1 expression was significantly correlated with several adverse clinicopathologic features including high TNM stage, presence of vascular tumor emboli, and high pre-operative serum $\alpha$-fetoprotein levels, but not correlated with tumor size. The results of the present study demonstrated that the expression of PD-1 in HCC tissues was significantly correlated with tumor size and the degree of differentiation, moderately correlated with venous thrombosis, and not correlated with clinical characteristics, including sex, age, cirrhosis, hepatitis B infection, TNM stage or tumor location. Hepatitis B and C viruses are major causes of HCC, although the underlying pathophysiological mechanisms are unclear (45). Notably, a previous study reported that the PD-1/PD-L1 signaling pathway is associated with cytotoxic $\mathrm{CD} 8{ }^{+} \mathrm{T}$-cell responses in virus-infected hosts, with reduced PD-1 expression observed following treatment-induced suppression of HBV replication in vivo (46). By contrast, the present study did not observe an association between PD-1 expression and hepatitis B viral infection. These inconsistent results may be due to the use of different sample sources, as well as differences between epitopes and the structures of the antibodies used.

There were several limitations of the present study. Morphologically, HCC is highly heterogeneous, and therefore, small tumor tissue samples are unlikely to represent an entire tumor. Further research involving a large number of randomized samples may enable researchers to investigate the practical application of using PD-1 mAbs in the diagnosis and treatment of HCC. In addition, the present study was unable to analyze the correlation between PD-1 expression and patient prognosis, due to the short follow up period. Furthermore, in addition to the biological characteristics of tumors, a number of additional factors are known to affect patient prognosis, such as liver function $(47,48)$. At present, the association between PD-1 expression and the prognosis of HCC remains unclear; however, a number of studies have demonstrated no significant correlation between PD-1 expression and the postoperative survival rate of patients $(48,49)$. By contrast, Hersey et al (50) reported that the expression level of PD-1 on CD8 ${ }^{+} \mathrm{T}$ lymphocytes in the peripheral blood of patients with primary $\mathrm{HCC}$ was significantly higher than that observed in the healthy subjects, chronic hepatitis B patients and cirrhosis patients, suggesting that the expression of PD-1 on $\mathrm{CD} 8^{+} \mathrm{T}$ lymphocytes was associated with primary liver cancer progression. In a study involving 65 patients with HCC, Gabrielson et al (51) demonstrated that the relapse rate of patients with tumor tissues containing a high density of $\mathrm{CD}^{+} \mathrm{T}$ and $\mathrm{CD}^{+} \mathrm{T}$ cells was lower $(\mathrm{P}=0.007)$ and exhibited longer recurrence-free survival rates $(\mathrm{P}=0.002)$ when compared with the group with a low number of infiltrating $\mathrm{CD}^{+} \mathrm{T}$ and $\mathrm{CD} 8^{+} \mathrm{T}$ cells. The present study did not assess the correlation between PD-1 expression and patient prognosis. However, the authors will monitor the outcomes of HCC patients recruited to the current study, and combine these observations with PD-1 expression in HCC tissues in order to examine the association between PD-1 expression and prognosis in a future study.

Previous studies have demonstrated that the proliferation and antitumor activities of $\mathrm{T}$ lymphocytes are inhibited when they express PD-1 (52), indicating that tumor-infiltrating $\mathrm{T}$ lymphocytes will undergo the whole process of cell activation and activity suppression until cell apoptosis (53). Therefore, PD-1 expression levels in tumor tissues may switch from low to high, and then decline according to alterations in T lymphocyte activity. This may explain why PD-1 is present in poorly differentiated tumors, as well as in well-differentiated tumors $(52,53)$. Nevertheless, the present study demonstrated that PD-1 expression was significantly associated with the degree of tumor differentiation. 
In conclusion, this study investigated PD-1 expression in HCC tissues using a novel anti-PD-1 mAb (9E11) as an alternative to commercially available antibodies $(44,54)$. The results indicated that high-level PD-1 expression may be an important factor associated with the immune checkpoint pathway in liver cancer, and that it may be a potential predictor of therapeutic response in a clinical setting. This will enable evaluation of the applicability of using a PD-1 inhibitor for the treatment of patients with HCC. Notably, the results indicated that patients with poorly differentiated tumors might benefit from anti-PD-1 mAb-based immunotherapy. Further research, with a large number of randomized samples to validate practical application is required. In order to identify a functional monoclonal antibody that inhibits HCC growth, future studies will continue to investigate the inhibitory effect of the prepared PD-1 mAbs on tumor cells and explore their antitumor mechanisms.

\section{Acknowledgements}

The authors gratefully acknowledge Yes Biotech Laboratories Ltd. (Mississauga, ON, L5S 1V6, Canada) for their technical assistance.

\section{Funding}

This project was supported by the Chongqing Program for Application and Development (grant no.cstc2014yykfA110022) and the Scientific and Technological Achievements Transformation Fund of the Third Military Medical University (grant no. 2015XZH19). The authors gratefully acknowledge the financial support received from the Scientific Research Project supported by Medical Health Charity Foundation of Beijing (grant no. YWJKJJHKYJJ-B16405 and YWJKJJHKYJJ-TLG17102).

\section{Availability of data and materials}

The data sets used and analyzed during the current study are available from the corresponding author on reasonable request.

\section{Authors' contributions}

ZL, BL and JC were responsible for the study design, original article drafting and editing, data acquisition and data analysis. $\mathrm{ZL}$ and $\mathrm{BL}$ were major experiment operators and contributors in writing the manuscript. DP, HX and PL gave advice on the experiments and writing of the manuscript. GW was responsible for immunohistochemical evaluations and data analysis. JW revised the manuscript and determined the isotype and titers of the monoclonal antibodies. GY provided technical assistance for the preparation of PD-1 mAbs. All authors read and provided final approval for the submission.

\section{Ethics approval and consent to participate}

The use of human tissues was approved by the Ethics Committee of Daping Hospital and Research Institute of Surgery, Third Military Medical University, and informed consent for participation in the study or use of their tissues was obtained from all participants. Procedures involving animals and their care were conducted in Yes Biotech Laboratories registered animal facility (License Number 0107-01) under the Animals for Research Act at the supervision of Ontario Ministry of Agriculture, Food and Rural Affair, Canada. The procedures and pain level assessment were reviewed and approved by Yes Biotech Laboratories Animal Care Committee and complied with the Animals for Research Act.

\section{Consent for publication}

Publication of the clinical datasets in this study does not compromise anonymity or confidentiality or breach local data protection laws.

\section{Competing interests}

The authors declare that they have no competing interests.

\section{References}

1. Benson DM Jr, Bakan CE, Mishra A, Hofmeister CC, Efebera Y, Becknell B, Baiocchi RA, Zhang J, Yu J, Smith MK, et al: The PD-1/PD-L1 axis modulates the natural killer cell versus multiple myeloma effect: A therapeutic target for CT-011, a novel monoclonal anti-PD-1 antibody. Blood 116: 2286-2294, 2010.

2. Brahmer JR, Tykodi SS, Chow LQ, Hwu WJ, Topalian SL, Hwu P, Drake CG, Camacho LH, Kauh J, Odunsi K, et al: Safety and activity of anti-PD-L1 antibody in patients with advanced cancer. N Engl J Med 366: 2455-2465, 2012.

3. Tykodi SS, Brahmer JR, Hwu WJ, Chow LQ, Topalian SL, Hwu P, Odunsi K, Camacho LH, Kauh JS, Pitot HC, et al: PD-1/ PD-L1 pathway as a target for cancer immunotherapy: Safety and clinical activity of BMS-936559, an anti-PD-L1 antibody, in patients with solid tumors. J Clin Oncol 30: 2510, 2012.

4. Chen DS, Irving BA and Hodi FS: Molecular pathways: Next-generation immunotherapy - inhibiting programmed death-ligand 1 and programmed death-1. Clin Cancer Res 18: 6580-6587, 2012.

5. Horn L, Herbst RS, Spigel D, Gettinger SN, Gordon MS, Hollebecque and Kowanetz M: An analysis of the relationship of clinical activity to baseline EGFR status, PD-L1 expression and prior treatment history in patients with non-small cell lung cancer (NSCLC) following PD-L1 blockade with MPDL3280A (anti-PDL1). J Thorac Oncol 8: S364, 2013.

6. Powles T, Eder JP, Fine GD, Braiteh FS, Loriot Y, Cruz C, Bellmunt J, Burris HA, Petrylak DP, Teng SL, et al: MPDL3280A (anti-PD-L1) treatment leads to clinical activity in metastatic bladder cancer. Nature 515: 558-562, 2014.

7. Creelan BC: Update on immune checkpoint inhibitors in lung cancer. Cancer Contr 21: 80-89, 2014.

8. Stewart R, Morrow M, Hammond SA, Mulgrew K, Marcus D, Poon E, Watkins A, Mullins S, Chodorge M, Andrews J, et al: Identification and characterization of MEDI4736, an antagonistic anti-PD-L1 monoclonal antibody. Cancer Immunol Res 3: 1052-1062, 2015.

9. Massard C, Gordon MS, Sharma S, Rafii S, Wainberg ZA, Luke J, Curiel TJ, Colon-Otero G, Hamid O, Sanborn RE, et al: Safety and efficacy of durvalumab (MEDI4736), an anti-programmed cell death ligand-1 immune checkpoint inhibitor, in patients with advanced urothelial bladder cancer. J Clin Oncol 34: 3119-3125, 2016.

10. West EE, Jin HT, Rasheed AU, Penaloza-Macmaster P, Ha SJ, Tan WG, Youngblood B, Freeman GJ, Smith KA and Ahmed R: PD-L1 blockade synergizes with IL-2 therapy in reinvigorating exhausted T cells. J Clin Invest 123: 2604-2615, 2013.

11. Strome SE, Dong H, Tamura H, Voss SG, Flies DB, Tamada K, Salomao D, Cheville J, Hirano F, Lin W, et al: B7-H1 blockade augments adoptive T-cell immunotherapy for squamous cell carcinoma. Cancer Res 63: 6501-6505, 2003.

12. Hamanishi J, Mandai M, Ikeda T, Minami M, Kawaguchi A, Murayama T, Kanai M, Mori Y, Matsumoto S, Chikuma S, et al: Efficacy and safety of anti-PD-1 antibody (nivolumab: BMS-936558, ONO-4538) in patients with platinum-resistant ovarian cancer. J Clin Oncol 32: 5511, 2014. 
13. Hodi FS, Sznol M, Kluger HM, Mcdermott DF, Carvajal RD, Lawrence DP, Topalian SL, Atkins MB, Powderly JD, Sharfman WH, et al: Long-term survival of ipilimumab-naive patients (pts) with advanced melanoma (mel) treated with nivolumab (anti-pd-1, bms-936558, ono-4538) in a phase I trial. J Clin Oncol 25: 374-393, 2014.

14. Dong H, Strome SE, Salomao DR, Tamura H, Hirano F, Flies DB, Roche PC, Lu J, Zhu G, Tamada K, et al: Tumor-associated B7-H1 promotes T-cell apoptosis: A potential mechanism of immune evasion. Nat Med 8: 793-800, 2002.

15. Woo SR, Turnis ME, Goldberg MV, Bankoti J, Selby M, Nirschl CJ, Bettini ML, Gravano DM, Vogel P, Liu CL, et al: Immune inhibitory molecules LAG-3 and PD-1 synergistically regulate T-cell function to promote tumoral immune escape. Cancer Res 72: 917-927, 2012.

16. Mangsbo SM, Sandin LC, Anger K, Korman AJ, Loskog A and Tötterman TH: Enhanced tumor eradication by combining CTLA-4 or PD-1 blockade with CpG therapy. J Immunother 33 : 225-235, 2010.

17. Steidl C, Shah SP, Woolcock BW, Rui L, Kawahara M, Farinha P Johnson NA, Zhao Y, Telenius A, Neriah SB, et al: MHC class II transactivator CIITA is a recurrent gene fusion partner in lymphoid cancers. Nature 471: 377-381, 2011.

18. Francisco LM, Salinas VH, Brown KE, Vanguri VK, Freeman GJ, Kuchroo VK and Sharpe AH: PD-L1 regulates the development, maintenance, and function of induced regulatory T cells. J Exp Med 206: 3015-3029, 2009

19. Inman BA, Sebo TJ, Frigola X, Dong H, Bergstralh EJ, Frank I, Fradet Y, Lacombe L and Kwon ED: PD-L1 (B7-H1) expression by urothelial carcinoma of the bladder and BCG-induced granulomata: Associations with localized stage progression. Cancer 109: 1499-1505, 2007

20. Ahmadzadeh M, Johnson LA, Heemskerk B, Wunderlich JR, Dudley ME, White DE and Rosenberg SA: Tumor antigenspecific CD8 T cells infiltrating the tumor express high levels of PD-1 and are functionally impaired. Blood 114: 1537-1544, 2009.

21. Hirano F, Kaneko K, Tamura H, Dong H, Wang S, Ichikawa M Rietz C, Flies DB, Lau JS, Zhu G, et al: Blockade of B7-H1 and PD-1 by monoclonal antibodies potentiates cancer therapeutic immunity. Cancer Res 65: 1089-1096, 2005.

22. Okudaira K, Hokari R, Tsuzuki Y, Okada Y, Komoto S, Watanabe C, Kurihara C, Kawaguchi A, Nagao S, Azuma M, et al: Blockade of B7-H1 or B7-DC induces an anti-tumor effect in a mouse pancreatic cancer model. Int J Oncol 35: 741-749, 2009.

23. Wong RM, Scotland RR, Lau RL, Wang C, Korman AJ, Kast WM and Weber JS: Programmed death-1 blockade enhances expansion and functional capacity of human melanoma antigen-specific CTLs. Int Immunol 19: 1223-1234, 2007.

24. Curiel TJ, Wei S, Dong H, Alvarez X, Cheng P, Mottram P, Krzysiek R, Knutson KL, Daniel B, Zimmermann MC, et al: Blockade of B7-H1 improves myeloid dendritic cell-mediated antitumor immunity. Nat Med 9: 562-567, 2003.

25. Zhang Y, Huang S, Gong D, Qin Y and Shen Q: Programmed death-1 upregulation is correlated with dysfunction of tumorinfiltrating $\mathrm{CD} 8^{+} \mathrm{T}$ lymphocytes in human non-small cell lung cancer. Cell Mol Immunol 7: 389-395, 2010.

26. Rupa P, Nakamura S, Katayama S and Mine Y: Attenuation of allergic immune response phenotype by mannosylated egg white in orally induced allergy in BALB/c mice. J Agric Food Chem 62: 9479-9487, 2014.

27. Boyoglu-Barnum S, Chirkova T, Todd SO, Barnum TR, Gaston KA, Jorquera P, Haynes LM, Tripp RA, Moore ML and Anderson LJ: Prophylaxis with a respiratory syncytial virus (RSV) anti-G protein monoclonal antibody shifts the adaptive immune response to RSV rA2-line19F infection from Th2 to Th1 in BALB/c mice. J Virol 88: 10569-10583, 2014

28. Pali-Schöll I, Szöllösi H, Starkl P, Scheicher B, Stremnitzer C, Hofmeister A, Roth-Walter F,Lukschal A, Diesner SC,Zimmer A, et al: Protamine nanoparticles with CpG-oligodeoxynucleotide prevent an allergen-induced Th2-response in BALB/c mice. Eur J Pharm Biopharm 85 (3 Pt A): 656-664, 2013.

29. Webster WS, Thompson RH, Harris KJ, Frigola X, Kuntz S, Inman $\mathrm{BA}$ and Dong H: Targeting molecular and cellular inhibitory mechanisms for improvement of antitumor memory responses reactivated by tumor cell vaccine. J Immunol 179: 2860-2869, 2007.

30. Zhou Q, Xiao H, Liu Y, Peng Y, Hong Y, Yagita H, Chandler P, Munn DH, Mellor A, Fu N, et al: Blockade of programmed death-1 pathway rescues the effector function of tumor-infiltrating T cells and enhances the antitumor efficacy of lentivector immunization. J Immunol 185: 5082-5092, 2010
31. Marusich MF: Efficient hybridoma production using previously frozen splenocytes. J Immunol Methods 114: 155-159, 1988

32. Campbell AM: Monoclonal Antibody Technology. Elsevier Science Publishers, Amsterdam, p264, 1984.

33. Laemmli UK: Cleavage of structural proteins during the assembly of the head of bacteriophage T4. Nature 227: 680-685, 1970.

34. Detre S, Saclani Jotti G and Dowsett M: A ‘quickscore' method for immunohistochemical semiquantitation: Validation for oestrogen receptor in breast carcinomas. J Clin Pathol 48: 876-878, 1995 .

35. Wang BJ, Bao JJ, Wang JZ, Wang Y, Jiang M, Xing MY, Zhang WG, Qi JY, Roggendorf M, Lu MJ, et al: Immunostaining of PD-1/PD-Ls in liver tissues of patients with hepatitis and hepatocellular carcinoma. World J Gastroenterol 17: 3322-3329, 2011.

36. Shi F, Shi M, Zeng Z, Qi RZ, Liu ZW, Zhang JY, Yang YP, Tien $P$ and Wang FS: PD-1 and PD-L1 upregulation promotes CD8(+) T-cell apoptosis and postoperative recurrence in hepatocellular carcinoma patients. Int J Cancer 128: 887-896, 2011.

37. Keir ME, Butte MJ, Freeman GJ and Sharpe AH: PD-1 and its ligands in tolerance and immunity. Annu Rev Immunol 26: 677-704, 2008

38. Yuan F, Zhang LS, Li HY, Liao M, Lv M and Zhang C: Influence of angiotensin I-converting enzyme gene polymorphism on hepatocellular carcinoma risk in China. DNA Cell Biol 32: 268-273, 2013

39. Patel SP and Kurzrock R: PD-L1 Expression as a predictive biomarker in cancer immunotherapy. Mol Cancer Ther 14: 847-856, 2015.

40. Robert C, Ribas A, Wolchok JD, Hodi FS, Hamid O, Kefford R, Weber JS, Joshua AM, Hwu WJ, Gangadhar TC, et al: Anti-programmed-death-receptor-1 treatment with pembrolizumab in ipilimumab-refractory advanced melanoma: A randomised dose-comparison cohort of a phase 1 trial. Lancet 384: 1109-1117, 2014.

41. Meng X, Huang Z, Teng F, Xing L and Yu J: Predictive biomarkers in PD-1/PD-L1 checkpoint blockade immunotherapy. Cancer Treat Rev 41: 868-876, 2015.

42. Shen MQ, Sun CY and Liu ZJ: Expression and clinical significance of B7-H1 and PD-1 in primary hepatocellular carcinoma tissues. WJCD 16: 3110-3113, 2008.

43. Zeng Z, Shi F and Zhang M: Significance of PD-1 expression on $\mathrm{CD}^{+} \mathrm{T}$ lymphocytes from patients with hepatocellular carcinoma. Infect Dis Info 22: 83-85, 2009.

44. Chang H, Jung W, Kim A, Kim HK, Kim WB, Kim JH and Kim BH: Expression and prognostic significance of programmed death protein 1 and programmed death ligand-1, and cytotoxic T lymphocyte-associated molecule-4 in hepatocellular carcinoma. APMIS 125: 690-698, 2017.

45. Di Bisceglie AM: Hepatitis B and hepatocellular carcinoma. Hepatology 49 (Suppl): S56-S60, 2009.

46. Evans A, Riva A, Cooksley H, Phillips S, Puranik S, Nathwani A, Brett S, Chokshi S and Naoumov NV: Programmed death 1 expression during antiviral treatment of chronic hepatitis $\mathrm{B}$ : Impact of hepatitis B e-antigen seroconversion. Hepatology 48: 759-769, 2008

47. Joseph RW, Cappel M, Goedjen B, Gordon M, Kirsch B Gilstrap C, Bagaria S and Jambusaria-Pahlajani A: Lichenoid dermatitis in three patients with metastatic melanoma treated with anti-PD-1 therapy. Cancer Immunol Res 3: 18-22, 2015.

48. Hamid O, Robert C, Daud A, Hodi FS, Hwu WJ, Kefford R, Wolchok JD, Hersey P, Joseph RW, Weber JS, et al: Safety and tumor responses with lambrolizumab (anti-PD-1) in melanoma. N Engl J Med 369: 134-144, 2013.

49. Eto S, Yoshikawa K, Nishi M, Higashijima J, Tokunaga T, Nakao T, Kashihara H, Takasu C, Iwata T and Shimada M: Programmed cell death protein 1 expression is an independent prognostic factor in gastric cancer after curative resection. Gastric Cancer 19: 466-471, 2016.

50. Hersey P, Ribas A, Hodi FS, Kefford R, Hamid O, Daud A, Wolchok JD, Hwu WJ, Gangadhar TC, Patnaik A, et al: Efficacy and safety of the anti-PD-1 monoclonal antibody MK-3475 in 411 patients (pts) with melanoma. Asia Pac J Clin Oncol 10: 48-49, 2014.

51. Gabrielson A, Wu Y, Kallakury B, Jiang J, Wang H, Johnson LB, Island E, Fishbein T, Satoskar R, Jha R, et al: A high density of tumor infiltrating CD3 and CD8 cells to predict recurrence free survival in patient with hepatocellular carcinoma. J Clin Oncol33 (Suppl 3): 280, 2015. 
52. Curran MA, Montalvo W, Yagita H and Allison JP: PD-1 and CTLA-4 combination blockade expands infiltrating T cells and reduces regulatory $\mathrm{T}$ and myeloid cells within B16 melanoma tumors. Proc Natl Acad Sci USA 107: 4275-4280, 2010.

53. Keir ME, Liang SC, Guleria I, Latchman YE, Qipo A, Albacker LA, Koulmanda M, Freeman GJ, Sayegh MH and Sharpe AH: Tissue expression of PD-L1 mediates peripheral T cell tolerance. J Exp Med 203: 883-895, 2006.
54. Zeng Z, Shi F, Zhou L, Zhang MN, Chen Y, Chang XJ, Lu YY, Bai WL, Qu JH, Wang CP, et al: Upregulation of circulating PD-L1/PD-1 is associated with poor post-cryoablation prognosis in patients with HBV-related hepatocellular carcinoma. PLoS One 6: e23621, 2011. 